\title{
Re-imagining the future for desert Australia: Designing an integrated pathway for enhancing liveability
}

Digby Race ${ }^{1,2}$, Alfred M. Dockery ${ }^{1,3}$, Lisa Havas ${ }^{1,4}$, Catherine Joyce ${ }^{1,4}$, Supriya Mathew ${ }^{1,5}$ \& Bruno Spandonide ${ }^{1,6}$

1 = Cooperative Research Centre for Remote Economic Participation, Alice Springs, NT 0870, Australia;

$2=$ The Fenner School, The Australian National University, Canberra, ACT 2601, Australia;

$3=$ Curtin Business School, Curtin University,

4 = Charles Darwin University, Darwin, NT

5 = Charles Sturt University, Alice Springs, NT 0870, Australia;

$6=$

Correspondence: Digby Race, The Fenner School, The Australian National University, Canberra, ACT. 2601, Australia. Tel: +61(0)419 638 406. E-mail: digby.race@anu.edu.au

\begin{abstract}
Desert regions of the world comprise about $25 \%$ of the world's land surface and are home to 500 million people, yet are often portrayed as extreme places with resident communities marginalised from mainstream development. Australia has a relatively vast desert region, covering about $70 \%$ of the continent and home to about 200,000 people. As in most desert regions around the world, perceptions of hardship and isolation are enduring images with communities seen to be stoic yet in need of subsidies from the 'mainstream' economy. The multi-dimensional nature of the debate about the future of Australia's desert region often leaves policy makers with little overarching synthesis to guide public policy. This article draws together research on climate change, energy, housing and transport to provide a transdisciplinary analysis of how the desert region could become a highly liveable and prosperous area for existing and new residents.
\end{abstract}

Key words: Aboriginal peoples, remote communities, climate change, energy systems, housing comfort, liveability, transport. 


\section{Introduction}

Australia has a vast desert area which covers about 3.6 million $\mathrm{km}^{2}$ (about $50 \%$ of the continent's area), which is home to a sparsely settled population of about 200,000 people (Australian Bureau of Statistics, 2006). In a global context, the combined region of Australia's deserts comprise about $10 \%$ of the world's total area of desert, with the lowest human footprint of just 1 person per $\mathrm{km}^{2}$ (compared to the desert region of the Indo-Malay, which includes the Thar Desert of India, with a human footprint 151 people per $\mathrm{km}^{2}$ ) (United Nations Environment Program, 2006).

The desert region of Australia includes the traditional homelands of Aboriginal peoples (Australian Institute of Aboriginal and Torres Strait Islander Studies, 2008), and over the past 100 years has developed a mixed economy based on pastoral operations, government education and health services, gas and mining operations, and tourism. Despite the strength of the Australian economy over recent decades, many Aboriginal people living in the remote desert area have remained among the most marginalised in the country (Productivity Commission, 2014). The desert region in Australia remains a confounding challenge for policy makers and the private sector, and for local communities, seeking to develop its prosperity (Walker, 2015). A suite of inter-connected and reinforcing factors - economically, socially and environmentally - create what some have termed a 'desert syndrome' (Stafford Smith and Huigan, 2009). Poor economies of scale, high costs of living, weak connections to and remoteness from the 'mainstream' economy, limited education and employment opportunities, a warming arid climate and uncertain climate risks, combine to create a confronting context. Despite these well-recognised challenges, there are continuing calls that more needs to be done to enhance the liveability ${ }^{1}$ and business viability of central and northern Australia (Commonwealth of Australia, 2014).

Recent research by the authors, individually and collaboratively, has explored the issues associated with mobility and transport, housing comfort, and energy efficiency and provisioning, in the context of desert Australia. By drawing together sectoral research on these topics - key factors of liveability - this article provides a transdisciplinary synthesis of

\footnotetext{
${ }^{1}$ Liveability $=$ is a term used in this article that combines the interaction between people's physical and social environments (see Addison, 2013).
} 
these issues and analyses the connections, as a means of designing a pathway for enhancing the liveability of desert Australia. Indeed, the authors argue that the profound complexity of issues facing many Aboriginal people living in the desert region will only be satisfactorily addressed with deliberate transdisciplinary analysis that acknowledges the connections and inter-dependencies between the domains that comprise of people's lives (Kefalas, 2011). Only then will effective policies emerge that help to re-write the prevailing narrative about desert Australia.

\subsection{Desert regions in a global context}

The world's deserts occupy about $25 \%$ of the earth's surface, which is an area of about 34 million $\mathrm{km}^{2}$ (about three times the area of Europe). The desert areas of the world are mainly located in two fringes parallel to the equator at $25-25^{\circ}$ latitude in both the northern and southern hemispheres with a desert biome reflective of an arid climate (i.e. plants and animals adapted to an arid climate, large areas of bare soil and low vegetation cover shaped "... more by climatic pulses than by average conditions" (UNEP, 2006). The extreme and variable weather experienced in Australia's desert region has a profound impact on the natural ecology (Morton et al., 2011) and people's livelihoods (Stafford Smith and Cribb, 2009). Climate change projections indicate that the desert region of central and northern Australia will get hotter in the medium-term, say by 2050 (CSIRO and Bureau of Meteorology, 2014), challenging the survival of the native biota and human settlements. Yet deserts should not be viewed as being necessarily landscapes of despair:

True deserts are not the final stage of a process of desertification; they are unique, highly-adapted natural ecosystems, both providing life-supporting services on the planet and supporting human populations in much the same ways as in other ecosystems. (UNEP, 2006)

About 500 million people live in deserts and on the desert margins of the world, with people surviving "... with a panoply of behavioural, cultural and technological adaptations to the dry environments. Traditionally, desert livelihoods were of three types - hunter-gatherers, pastoralists, and farmers" (UNEP, 2006). The livelihoods of most desert peoples has changed to reflect their contemporary context (e.g. the emergence of service industries), with change leading to particular challenges for deserts given that their sparse populations, which are amongst the world's poorest in an absolute economic sense, tend to be remote from major 
markets and have only a soft, marginal voice in political decisions and policy making (Davies and Holcombe, 2009).

Well considered reform of the prevailing policies and development practices in the world's vast desert regions could start to bridge the inequality between the remote desert peoples and their city counterparts. After all, cities such as Riyadh (Saudi Arabia) and Phoenix (United States of America) illustrate that desert environments need not confine its peoples to hardship or poverty. Yet for Aboriginal peoples in desert Australia, the colonisation process has caused a profound change in their lives (Tonkinson, 2007) and left many with poor livelihoods (Productivity Commission, 2014).

\subsection{Drivers of change}

While a 'driver' of change can be simply defined as a source of influence, in the context of understanding the multiple impacts of change on a community, the concept is more complex when the whole system in which people live is experiencing impacts from a range of drivers - such as, the fluctuating economy, changing government policies, varying education and employment opportunities, climate variability, and demographic change. There are often multiple drivers of change impacting on people's lives from different sources, times and dimensions (Braimoh, 2009; Seabrook et al., 2011; Batterbury and Bebbington, 1999). Sometimes change can be accelerated when multiple drivers work in synergy, and conversely powerful drivers of change may be moderated when different phenomena work in opposite directions (Brook et al., 2008). Further complicating this understanding is that some drivers may cause impacts on people's lives long after the source of influence has ceased.

The variable climate of, and projected climate change for, central Australia remains a powerful driver of liveability and business viability. While people and businesses in remote Australia have always exhibited an innate capacity to cope with variable and extreme weather, the full impacts of climate are not always well understood. If the liveability of desert Australia is to be enhanced, greater consideration of how people can thrive in this desert region is needed - rather than just coping or surviving. While there is growing evidence that people and businesses are adapting to extreme weather, there is a lack of reliable locallyspecific information about how to invest in transformative change that is positive, strategic and long-term, and whether increased economic development can overcome the challenges of climate change facing desert Australia. 


\subsection{Unpacking 'development'}

The underlying essence of human economic activity is to sustain our livelihoods (Ray, 1998). More specifically, economic activity may be driven by efforts to maintain or increase the current or future livelihoods of those participating within a given financial system - the economy, yet too often with damaging trade-offs (Barbier, 1987; Turner, 1988). The trade in goods and services between people, regions and countries, is underpinned by a simple economic theory, that the production, distribution and consumption of goods and services will improve the livelihoods of those involved in the activity. The increase in economic wealth by communities and organisations leads to a process of capital growth and industrialisation (often measured as Gross Domestic Production) - a process that is often referred to as economic development.

While this concept of 'development' often goes unchallenged, it becomes particularly contentious when it clashes with indigenous cultures and values, such as amongst remote Aboriginal communities in Australia's desert region. For example, maximising economic activity is not a galvanising mantra in communities that have 'caring for Country' at their core (Moran et al., 2007; LaFlamme, 2010). While the Western 'materialist' narrative of economic development often appears to overwhelm indigenous cultures (Groenfeldt, 2003), building the capacity of Aboriginal communities to articulate and pursue their preferred futures is required to enhance the liveability of the desert region.

Beyond this debate, there is a wide range of views and theories on how economic development functions, its implications, and the best strategies to optimise the benefits, leading to the concept of 'sustainable development' that has been popularly used since the 1980s (Lélé, 1991). Although the term has been criticised for being too narrow and vague (see Fig. 1, below), it has remained popular among policy makers as a worthy goal, albeit somewhat aspirational. 


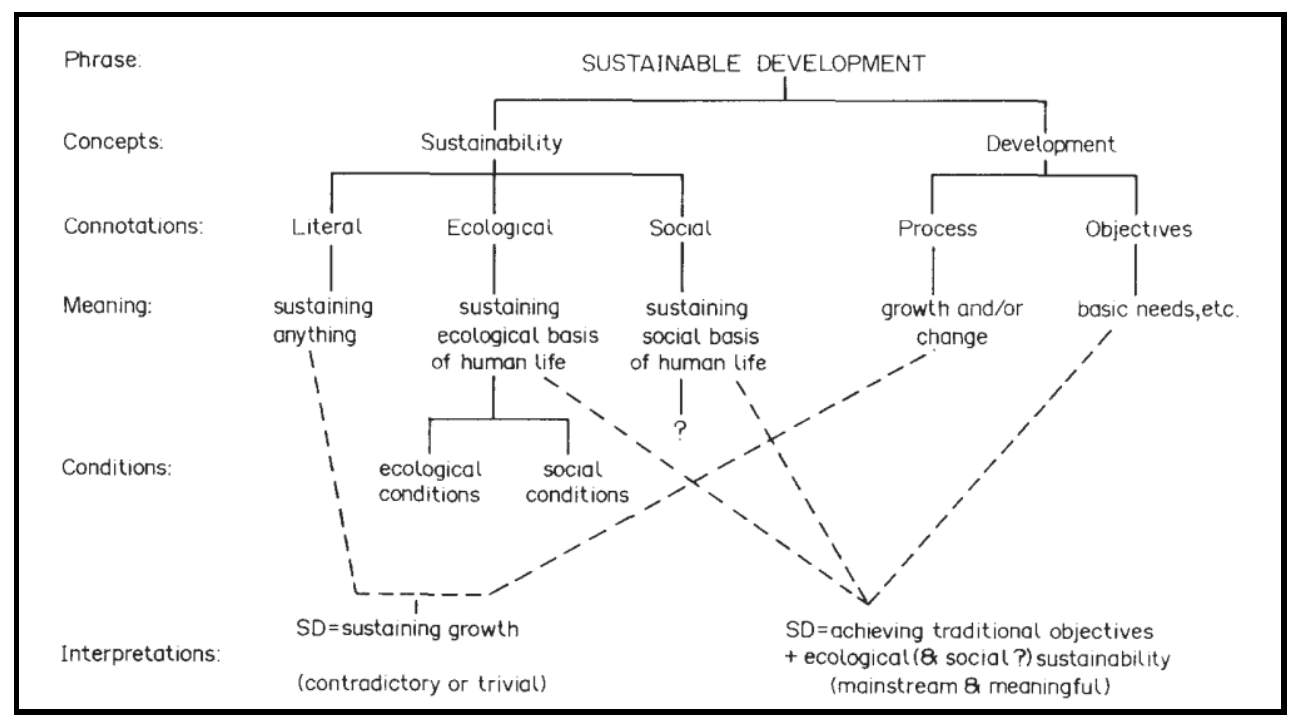

Figure 1: Diagnostic of sustainable development (Lélé, 1991, p. 608)

Over centuries, and particularly the $20^{\text {th }}$ century, economic development has transformed the lives of billions of people - from livelihoods of subsistence to lives with greater opportunities and prosperity. During 1950-2000 there was a sevenfold increase in the world's economic activity. However, for some time analysts have raised concerns that economic development does not always improve the livelihoods for all (Groenfeldt, 2003), even if GDP is increasing. Indeed, an increasing GDP of a country can mask a decline in livelihoods and increasing poverty of some of its citizens - with economic development not always consistent with social development. A marked disparity in prosperity between urban and remote Australia is evident, particularly for many living in remote Aboriginal communities (Productivity Commission, 2014).

Even the economic theory of 'comparative advantage', where communities will tend to undertake economic activity for which they have a natural advantage compared to others within the wider market, appears to fail when applied to remote Australia. The comparative advantage of remote Australia, with its vast gas and mineral wealth can fail to generate a proportionate wealth for local communities (Tiplady and Barclay, 2007).

In this article, we draw on disciplinary-based and sectoral research conducted within the context of desert Australian to provide an integrated analysis of how the region could be transformed into a highly liveable area. Transdisciplinary analysis offers potential to inform policies so that opportunities for enhanced liveability in desert Australia become the focus, 
rather than seeking to move people out of 'unviable' remote locations and into regional and urban centres. A conceptual diagram is used to understand the elements and connections that comprise the desert system, and challenges posed by future climate change and likely impacts on vital sectors such as energy, housing and transport (see Fig. 2). The following sections discuss each of these elements identified in Figure 2.

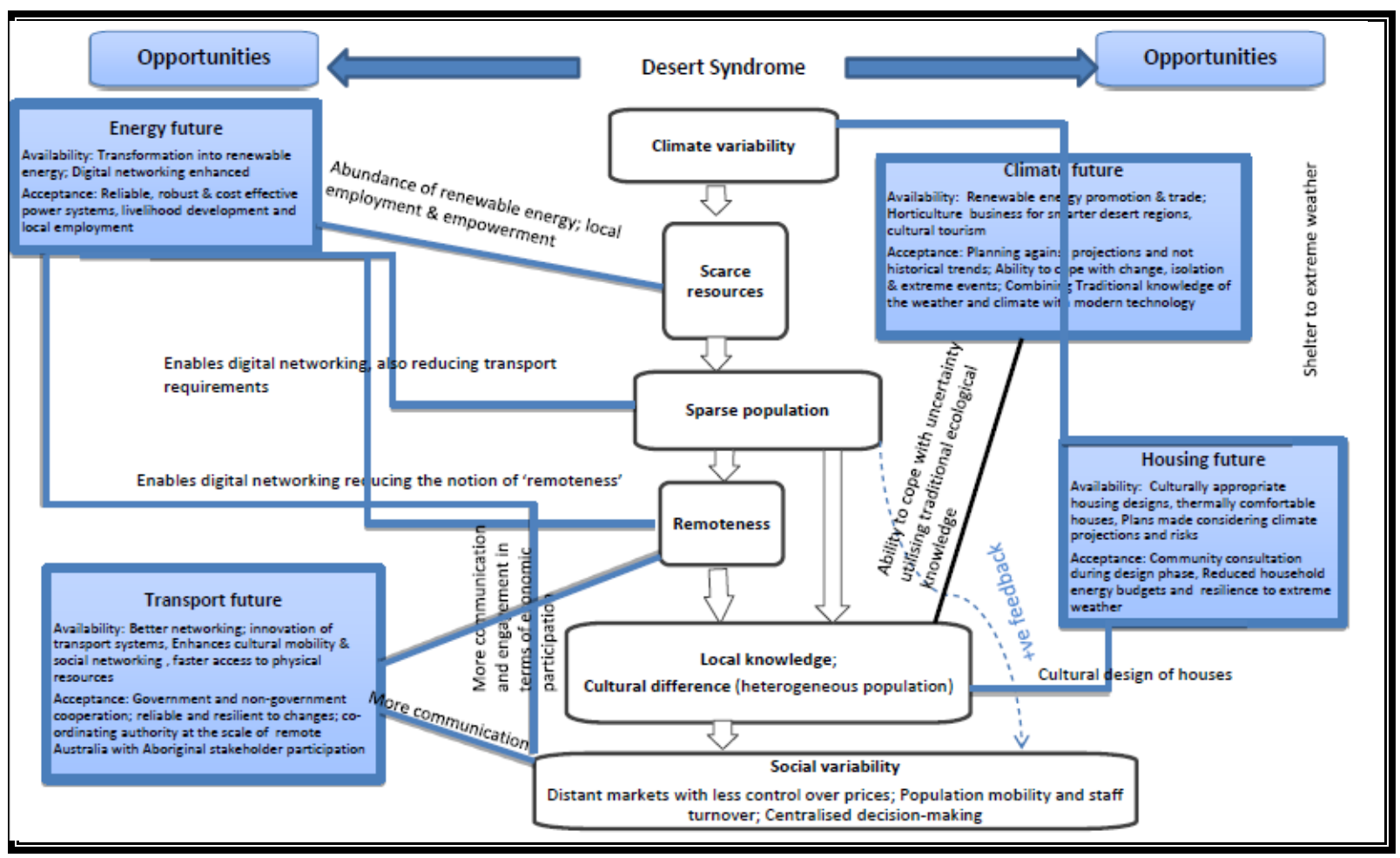

Figure 2: Livelihood system in desert Australia (authors)

\section{Climate change impacts on desert people and liveability}

A critical issue that has received considerable attention over recent years has been that of human-induced climate change - the economic and social costs of impacts, adaptation and mitigation (e.g. Stern, 2006; Garnaut, 2008). The UNEP (2006) reported that the "Average projected changes for 2071-2100 show a temperature increase of between one and seven degrees Celsius in all world deserts." This is consistent with the projection for Australia, which is likely to face a rise in average temperatures in the range $2-7{ }^{\circ} \mathrm{C}$ by 2100 (IPCC, 2014). 
While people live in a wide range of climate zones in Australia (tropic to cool temperate), and have varying capacities to adapt to the impacts of climate change (Jendritzkyl and Tinz, 2009), the desert region of central Australia is likely to face greater warming compared to the neighbouring coastal zones. Also, people living in the desert region are likely to be at greater risk from climate change due to higher levels of vulnerability and lower adaptive capacity, than people living in Australia's urban centres (Addison, 2013).

Climate change is more than just an environmental issue and is considered by many to be a major driver of change throughout Australia's economy - with direct impacts of more extreme weather, and the anticipation of future impacts (e.g. increasing insurance premiums for flood, fire, storms). There are also a wide range of direct impacts of climate change on people, such as heat stress and spread of tropical diseases, as well as increasing disruption to energy and transport systems due to flooding or storm damage. There are also the direct and indirect impacts on natural systems (e.g. drying water bodies, altered fire regimes, spread of feral animals and weeds, altered health and regeneration of native biodiversity).

The direct impacts of climate change for people in desert Australia are expected to be largely from heat stress (Addison, 2013; McMichael et al., 2006) and the increasing energy requirements to cope with hot weather. An increase in hot weather (i.e. higher temperatures and extended summer periods) will mean less comfortable conditions for living and working in desert Australia - a reduced liveability. It is anticipated that heat stress will be felt most acutely by people working outdoors and living in housing with poor thermal control. Less comfortable living conditions for extended periods leads to greater prevalence of fatigue, illness and emotional stress; thereby eroding people's coping capacities at the individual, family and community levels. The flow-on impacts of prolonged discomfort are declining engagement with education and employment opportunities, diminishing contributions to family and community, and withdrawing from social activities - conditions likely to exacerbate feelings of isolation and poor mental health.

Temporary mobility in desert Australia, and in some industries, may have been an effective strategy for managing climatic variability in the past (e.g. moving away when intense storms are anticipated), but it is difficult to provide high levels of health and social support services, particularly when seeking to address chronic health issues. Also, more intense storms are anticipated to cause flooding, increased illness and injury amongst residents, damage to 
infrastructure and housing, restricted road access and degraded tele-communication (Addison, 2013), placing increased pressure on community-based health clinics and staff. Intense storms are expected to restrict the travel of health professionals or make relocating patients more difficult - at a time when the need for professional healthcare is most acute (National Climate Change Adaptation Research Facility, 2014).

\subsection{Adapting to climate change}

A combination of behavioural adaptation (e.g. increasing fluid intake, utilising cooler areas such as shopping centres, shade of trees) and use of infrastructure that provides capacity to moderate air temperature (e.g. housing) form the basis of current adaptation to hot weather in desert Australia. Aboriginal communities are increasingly dependent on housing, public building and electrical appliances such as ceiling fans and air-conditioners to adapt to hot weather (Race et al., 2015a). Although Aboriginal communities in the desert region exhibit vulnerability (low socio-economic conditions) and resilience (enduring culture and presence in the desert region) to harsh climates (Maru et al., 2014), their dependence on modern technology to modify extreme weather is likely to increase their vulnerability if their adaptation strategies become less accessible and less affordable in the future. Recent research already indicates that a proportion of the resident population in central Australia experience 'energy poverty' by spending almost $10 \%$ of their income on electricity costs (Race et al., 2015b). This situation is likely to be made worse under climate change if transformative measures are not pursued, such as the widespread construction of energy efficiency housing. The current energy sources in remote Australia are a mix of diesel, natural gas and a small proportion of renewable such as solar and wind. Small remote communities are usually not connected to a central grid and are thus reliant on diesel generators for power. Most locations in desert Australia are categorised as 'very remote' (ABS, 2015) based on their distance to major service centres and transport access. The sparse road networks in desert Australia, unlike in other desert locations such as Abu Dhabi or Phoenix (Maru et al., 2014), affect the proper functioning of remote communities due to high transportation costs of diesel and disruption to fuel supplies during floods and storms.

Central Australia has been assessed as having an abundance of renewable energy, such as solar energy (Geoscience and ABARE, 2010), to enable greater self-sufficiency and creating considerable employment if the region was to become a major exporter of renewable energy (Pittock, 2009). The projections of climate change in central Australia indicate people will 
seek to use more energy at the household and community levels, as a means of moderating extreme temperatures. The combination of climate change and energy use should inform the transformation of energy generation to affordable renewable sources, and thereby enhancing liveability of the region.

\section{Mobility and transport in desert Australia}

\subsection{Remote mobility}

While there are a range of economic, physical and technical constraints acknowledged as important issues in desert Australia (e.g. long distances, sparse population, high living costs, uncertain climate), some argue that socio-cultural factors lie at the core of the issues facing Aboriginal communities living in this region. The clash between the 'mainstream' Western culture and the traditional Aboriginal culture has eroded the cultural continuity and identity that is critical to the wellbeing of indigenous peoples (Chandler et al., 2003; Groenfeldt, 2003; Cairney and Abbott, 2014).

Some of the cultural destruction is the result of past policies of oppression, such as removal of children and dispossession of traditional lands (Tonkinson, 2007), but much is simply the consequence of the enduring juxtaposition of traditional Aboriginal and contemporary Western socio-economic systems. As models of infrastructure and service provision predicate upon economies of scale (large populations) (Markham and Doran, 2015) and sedentary populations encroach upon remote communities, such communities increasingly appear 'non-viable', 'uneconomic' or 'unsustainable'. Culture then becomes seen as the cause of disadvantage, leading to a prevailing paradigm in policy circles of assimilation into the mainstream as the solution (Pickering, 2000). Mobility is one of those aspects of culture that is seen as 'problematic' (Dockery, 2016) for improving outcomes for Aboriginal peoples in desert Australia, as noted by others:

The concept of Indigenous temporary mobility has come into prominence as a way of capturing an aspect of indigenous culture critical to the explanation for the disadvantage experienced by Australia's Indigenous peoples, including adverse housing outcomes. (Habibis et al., 2011, p. 3)

Temporary mobility is critical to cultural maintenance as it facilitates family and kinship networks, attachment to and obligations to traditional lands and participation in ceremonies 
and other cultural obligations. Moreover, these traditional drivers of mobility have proven to be remarkably persistent:

Attachment to place and community prevail, irrespective of a history of changing government policies. There appears no reason to expect that these attachments will change in the foreseeable future. (Memmott et al., 2006)

Undoubtedly Aboriginal people face trade-offs when they choose remote community life over migration to larger population centres. In a sense, mobility becomes the arbiter between what each location has to offer, providing continuity of culture and strong connections to traditional country (homeland) on one hand, and on the other hand access to cheaper goods, education and health services and the amenities available in large regional centres. Dockery (2016) argued that mobility should be seen first and foremost as a means to accessing those things that contribute to a person's wellbeing, an approach that gives equal weight to cultural and mainstream objectives.

Acceptance of the importance of mobility, reduction in transport costs, improved socioeconomic networks, affordable and sustainable energy systems, improved models of service delivery (notably health and education), and more reliable tele-communications, can all be brought together into a single narrative to expand and improve the choices available to Aboriginal peoples living in remote desert Australia.

\subsection{Roadmap for desert transport}

Transport systems are crucial for the economic and social participation of remote communities and enterprises, and their subsequent livelihoods and wellbeing. Desert Australia has a 'two speed' transport system characterised by a state-of-the-art aviation network for those who can afford its use, while the majority of Aboriginal and Torres Strait Islander people living in remote Australia lack access to reliable private and public transport for even localised travel (Spandonide, 2014). Aboriginal people living in small desert settlements are acutely affected by a lack of transport options (Memmott et al., 2006; Hurni, 2007).

The acute shortage of vehicles and transport services has prompted a range of 'grass roots' adaptations, such as unconventional maintenance and repair of vehicles, car 'pooling' (sharing) and simplified payment systems. The challenge has also prompted innovation 
within the government and private sectors, with the design of the Centre Bush Bus model that provides public transport options for a large network of remote communities (see http://centrebushbus.com.au/). Other examples include the use of long road trains (freight trucks), and the emergency medical aeroplane service - The Royal Flying Doctor Service (http://www.flyingdoctor.org.au/). While these examples illustrate the innovation of transport systems servicing desert communities, there is in many cases a sharp divide between who can and cannot afford access to the various transport options.

Transport systems in desert Australia can often fail to be effectively integrated (e.g. linking between different transport modes), or coordinated (e.g. uncoordinated across State/Territory boundaries). As a result, public transport services often operate in a highly monopolistic market with partial network coverage and reduced network integration at the local and regional levels - a typical characteristic of areas with smaller population densities (Velaga et al., 2012). However, in a context with limited transport options, any available option tends to have a high return on social value, even if financially unviable, as some level of transportation is needed for remote communities.

Given the long distances typically travelled by people living in desert Australia, there remains a high dependency on conventional fuels - with electric and hybrid-fuel vehicles currently dismissed as unviable because of the limited range and lack of recharge equipment (Went et al., 2008; Diesendorf et al., 2010). Moreover, vehicles fitted out with new hybrid or electric technologies are anticipated to be more expensive to purchase, especially heavy duty vehicles designed for off-road terrain that are commonly used in desert Australia. Conversely, the combined benefits that the use of long-range electric vehicles with extra-battery capacity might represent for very remote communities might be a 'game changer' for some remote communities, such as if purchased as a shared community vehicle and re-charged using renewable energy. Appropriate policies to support public transport and acquisition of appropriate vehicles and equipment will be a key driver of determining future transportation strategies (Hunter, 2012; Litman, 2014).

Climate change impacts are expected to affect interstate and international travel to desert Australia. Communities and enterprises will have to adapt to more frequent episodes of extreme temperatures, heavy rainfall and storms (Doll et al., 2014). The use of a local seasonal calendar as a standard part of business planning (e.g. to identify when transport 
systems might be constrained) may prove to be one of the most cost-effective way to adapt to seasonal predictions provided by the Bureau of Meteorology. Improved prediction of delays or disruptions to transportation will in turn improve community dynamics, as people would spend less time in transit or having services delayed. Over a longer time frame, the key transformative change will be the ability for transport systems to embrace new technologies that allow travelling speed to increase and a corresponding decrease in travel time, so to make more effective use of the traveller's time for both business and social activities (Brown and Gonder, 2014). Most importantly, a coordinating transport authority at the regional level to cover desert Australia would be beneficial for coordinating existing transport options and facilitating adoption of innovations, thereby beginning to close the gap in desert Australia's 'two-speed' transport system.

\section{Energy systems for remote desert communities}

As discussed above (section 2), enhancing the liveability in desert Australia over the longer term is likely to be tightly coupled with the availability of affordable energy, for households and businesses. While energy is generated and supplied via a diverse range of sources and mechanisms, there is an increasing need for a systematic approach to energy systems in central Australia. In the desert region, adequate and reliable energy systems enable access to water supplies and tele-communications, and contribute directly to good health, access to education and enterprise development.

Energy systems in Aboriginal communities living in the desert region are configured in a number of ways:

- For communities in proximity to large population centres, they may have access to a regional electricity grid;

- For large remote communities (i.e. $100+$ people), they are usually serviced with a 'stand-alone' power generator (often fuelled by diesel, but sometimes augmented with solar);

- For small remote communities (i.e. <100 people) or settlements, they are primarily responsible for generating household energy, which is usually comprised of a mix of sources: diesel and petrol generators, solar photovoltaics, passive solar, firewood. 
The typical energy systems constrain liveability in the desert region in two ways: physical availability and affordability. The physical availability of energy for remote communities is for the most part dependent on diesel for electricity generation, meaning that there are recurring costs for fuel and a number of environmental impacts from transportation, storage and combustion. There is a limited ability for currently installed systems to be expanded easily, constraining future liveability and enterprise development. The increasing cost of providing energy to 'serviced' communities has prompted governments to initiate household 'energy efficiency' programs and to work with public and community housing organisations to retrofit thermally inefficient houses. The primary aim of these programs is to reduce the amount of residential energy used in remote communities and thereby avoid, or at least delay, expenditure on expanding or replacing existing energy systems.

In smaller communities who supply their own energy, the physical availability of energy services is highly varied. Most communities have small diesel or petrol-fuelled generators and some may have additional solar photovoltaics with a battery component for storage. The second energy-related issue that constrains liveability in remote Aboriginal communities is the affordability of energy for households, with 'energy poverty' becoming a prevalent phenomenon (Race et al., 2015b).

The use of electricity to cool thermally inefficient houses means that the cost burden of climate change will be on the householder, exacerbating 'energy poverty' for many households in desert Australia. Over time, the increases in electricity consumption will require an ongoing increase in capacity of local and regional energy systems which will, in turn, increase costs for supplying electricity within both self-provided and 'serviced' communities in desert Australia.

\subsection{Adapting to changing energy futures}

Making a number of changes to the way people live and work in desert Australia can be complex, because some of the changes may require purchasing expensive new appliances for homes (e.g. an energy efficient fridge) or equipment for work (e.g. solar powered water pumps), and so each change needs to be carefully assessed to ensure it provides the anticipated benefits and is positive to overall livelihoods. There is also a need to consider the accumulative effects of many small changes, to ensure small individual changes are complementary to other changes and lead to an enhanced liveability (Adger et al., 2009; 
Grothmann and Patt, 2005). For example, if a household installs several new air conditioners to cool their home on hot summer days, this may make the daytime air temperature in the home more comfortable but also cause an unfortunate increase in the household's electricity bills. Exploring alternate and cheaper options to cool homes is likely to be more effective adaptation to very hot weather, hence the interest and role of the Alice Solar City (ASC) initiative (Havas et al., 2015a).

It is difficult to detect the direct impact of individual incentives but there was a significant inverse correlation between the number of energy efficiency measures adopted by households and energy consumption (Havas et al., 2015b). However, adoption of energy efficiency measures through the ASC program alone did not result in a significant reduction in electricity use and consequently no financial saving when compared to the wider Alice Springs community. An important finding from this research is that households that adopt a renewable energy technology, either a photovoltaic system or a solar hot water system achieved financial savings on electricity consumption without changing household behaviour. The connection between effective use of measures, coincident behavioural change or increased energy awareness and greater energy reduction are important factors in understanding energy conservation (Havas et al., 2015b).

\section{Desert housing: a shelter from the storm}

Current housing in desert Australia may not be sustainable with climate change beyond particular threshold temperatures due to increasing peak electrical demand and energy costs as people become more reliant on air-conditioning. A number of adaptation strategies will be required to assist remote communities in adapting to hotter environments. A combination of transitional and transformational adaptive measures have already been implemented in Alice Springs (the major service town of central desert Australia) which includes 7-star rated houses for the newly built/refurbished town camp buildings introduced as part of the Strategic Indigenous Housing and Infrastructure Program (SIHIP) (see CAT, 2013) and various energy efficiency and renewable energy incentives rolled out through the Alice Solar City program (see ASC, 2013). 
Some studies suggest improving the energy efficiency of housing as a cost effective measure (Ren et al., 2011) as it requires only adding insulation to the already existing building stocks and many local efforts in central Australia have also been focusing on such strategies (e.g. SIHIP houses built on a 7-star standard). Australia has now a National Construction Code which includes mandatory requirements for energy efficiency and thermal comfort of new residential housing, with new houses required to meet a minimum standard of 6-star rating (e.g. in the States of Western Australia and Queensland), with the exception being the Northern Territory which has a minimum 5-star rating. A minimum 5-star rating for new buildings may not be an adequate long term heat management strategy as climate change may reduce the energy efficiency of housing to an equivalent rating of 3.4-stars in 2050, and 1.5stars by 2100 (under an AIF1 fossil fuel intensive scenario) in central Australia (see Wang et al., 2010).

\subsection{Enhancing housing comfort}

In desert Australia, houses may be considered as a mode of adaptation that provides adequate thermal comfort and protection against severe weather (Race et al., 2015b). This also means it is important to achieve the desired thermal comfort without creating additional pressure on household living costs. Recent research has revealed a strong correlation between socioeconomic and demographic characteristics with household energy usage. That is, higher household income, larger sized houses (floor size), and fewer household members correlate with higher energy use (Lenzen et al., 2006; Newton and Meyer, 2012). For example, higher income households are likely to contain more appliances than households with lower incomes, with one study showing that there has been a substantial increase in energy consumption due to the increasing use of a range of home entertainment and kitchen appliances (Taylor et al., 2010). However, households with young children ( $<5$ years of age) and older members also correlate with higher energy use (Brooks and Yusuf, 2009).

While renewable energy (e.g. solar) appears a viable option for desert Australia, a challenge for policy makers and researchers is to better understand the drivers that influence the adoption of such technology and changes in behaviour leading to household energy efficiency. Understanding the particular drivers for different socio-economic groups of households may inform strategies to promote and support adoption of energy efficiency technology and changes in behaviour. For instance, some of the complexity of this topic is that provision of credible information tends to result in higher levels of knowledge, but this 
does not necessarily translate into behavioural changes in favour of energy efficiency. Also, financial rewards and incentives generally lead to energy conservation, but tend to be shortlived. Personalised regular feedback on household energy usage has been found to be valuable in shifting household behaviour towards greater energy efficiency (Abrahamse et al., 2005).

Education programs and incentives seeking to improve household energy efficiency will need to be culturally appropriate, household focused (e.g. age, number and behaviour of residents) and tailored for specific climate zones (Race et al., 2015b). For example, a '5-star' energy rated house in Alice Springs may need to adopt an integrated strategy that includes using energy efficient appliances, retrofitting to a '7-star' rating and installing photovoltaic technology that may be required to restrict household energy consumption to current levels as the climate warms by 2 to $7 \circ \mathrm{C}$ (Ren et al., 2011). It will be important to invest in upgrading the energy 'star' rating of housing taking into consideration location specific, climate projections.

\section{Conclusions: Opportunities for desert Australia}

Desert Australia is already characterised by high daytime temperatures, low levels of rainfall, low population density and remote access to 'mainstream' services (Race et al., 2014; Maru et al., 2012). These conditions are likely to be exacerbated in future scenarios of climate, demographic and economic changes with projected increases in average temperatures and living costs (Race et al., 2011; Addison, 2013). Most scenarios of desert Australia portray remote Aboriginal communities continuing to detach from the dominant Western model of 'mainstream' development. This image reinforces the widespread view people generally have of deserts, in Australia and elsewhere, that the environment is harsh and unforgiving.

It is hard to construct a plausible alternative future for desert Australia when an increasing number of sectoral analyses and popular media feed a prevailing narrative of desert communities needing government-driven development and expensive support. However, when alternatives and options are explored, and melded across disciplines, a very different future for desert Australia can emerge. The transdisciplinary synthesis presented in this article reveals some critical elements and connections in a system that can be re-wired, so that 
physical structures, social institutions and networks, and commercial enterprises are redesigned for positive transformational change - change that enhances the liveability of desert Australia. In the absence of deliberate transdisciplinary analysis, the hazards and weaknesses in complex systems can be difficult to identify (Sircar et al., 2013).

The desert landscapes of Australia will remain important homelands for the traditional Aboriginal owners and the more recently arrived non-Aboriginal people - in part because these landscapes remain a critical part of their cultural heritage, provides for their current livelihoods, and offer future opportunities. Indeed, there are towns in the Australian desert (e.g. Alice Springs) with a diverse local economy, infrastructure that is connected to the mainstream economy, a vibrant social life and a distinctive cultural heritage (e.g. Central Desert art). These characteristics are shared with many other desert regions of the world, such the area surrounding Santa Fe in New Mexico (USA), the Thar Desert in Rajasthan (India) and the Sahara desert across the countries of northern Africa. The systems thinking described in this article may inform options for transformational development in other desert regions of the world, where energy efficiency, housing comfort, health and wellbeing are tightly coupled factors that contribute to the liveability of any region.

Recent research explored some of the opportunities and challenges for desert people in relation to local norms, identities, knowledge systems, governance and livelihoods from broader scale processes and institutions to enable transformational change (Davies and Holcombe, 2009). Using a 'strength based' approach (rather than a 'deficit' approach) that builds on the positive characteristics of desert communities, some key strategies to enhance desert Australia include:

- Utilising the strong social relationships (high social capital) commonly observed among the Aboriginal communities in desert Australia. Improving telecommunication will enable information exchange (communication) and mobility to become more closely linked, rather than erstwhile impediments to each other allowing high levels of 'digital' connectivity and mobility.

- Improving the coordination of existing transport options into a robust system (i.e. linking transport modes across governance boundaries). Investing in 'digital' 
connectivity may be more cost-effective (e.g. by reducing demand for conventional transport) than just investing in the conventional physical transport infrastructure.

- Encouraging investment and innovation in improved housing: supporting capital investment and local innovations that improve housing standards, such as a shift to 7 star and 10-star energy efficiency homes - with the 'star' rating of housing mandatory information when buying and selling real estate (required information by banks/finance companies, with more favourable terms for higher 'star' ratings). Also designing houses to suit the cultural differences of the heterogeneous population living in desert Australia (e.g. large family groups, single people).

- Transitioning to sustainable energy systems: foster local 'ownership' of energy systems that can transition to appropriate sustainable energy generation, such as moving to a gas-solar hybrid energy production (e.g. gas-fired turbines for energy generation at night time and contingencies), that may see energy costs reduce. In the longer term, re-wiring the economy so it is powered by a localised renewable energy system and away from imported fossil fuels.

Overall, the above elements need to be drawn together into 'liveability hubs' where appropriate options for education and training, employment, health and wellbeing services, art and culture, sports and recreation are coordinated and integrated. The very nature of such hubs can challenge the prevailing arguments about 'economies of scale' and 'critical mass' that dominate notions of development. Re-considering community 'viability' in desert Australia will be essential. Liveability hubs should be progressively designed and maintained by expertise and skills within the local community, thereby reducing the dependence upon 'outsiders' to be sustained. Improved water use, housing comfort, energy production and reenergised local enterprises (e.g. art, food, tourism) could underpin the desert region's future. These strategies could be further developed and nuanced for the other major desert regions of the world, so that there can be a change in the narrative about the world's deserts, from places of constraint and limitation to sources of innovation and prosperity.

While there will always be uncertainty about future conditions and challenges, investing in strategies that are culturally-appropriate, of low regret (low risk) and provide multiple benefits appears the best pathway. That is, investing in the connectivity and mobility of remote communities, creating a coordinated transport system, transitioning to renewable 
energy, and building super energy efficient housing can all be elements of re-designing the liveability of desert Australia.

\section{Acknowledgements}

This article draws on the authors' individual and shared research, which was partly funded by the Australian government through the Cooperative Research Centre for Remote Economic Participation. 


\section{References}

Abrahamse, W., Steg, L., Vlek, C. and Rothengatter, T. 2005. A review of intervention studies aimed at household energy conservation. Journal of Environmental Psychology, 25: 273-291.

Australian Building Codes Board (ABCB) 2006. Protocols for housing energy rating software. www.abcb.gov.au/

Addison, J. 2013. Impact of Climate Change on Health and Wellbeing in Remote Australian Communities: A Review of Literature and Scoping of Adaptation Options. CRC-REP Working Paper CW014. Alice Springs, Ninti One Limited.

Adger, W.N., Dessai, S., Goulden, M., Hulme, M., Lorenzoni, I., Nelson, D.R., Naess, L.O., Wolf, J. and Wreford, A. 2009. Are there social limits to adaptation to climate change? Climatic Change, 93: 335-354.

Alice Solar City (ASC) 2013 Alice Solar City energy champions 2008-2013. www.alicesolarcity.com.au

Armitage, D. 2007. Building Resilient Livelihoods through Adaptive Co-Management: the Role of Adaptive Capacity. Adaptive Co-Management: Collaboration, Learning and Multi-Level Governance U. Press. Vancouver, Toronto: pp. 62-82.

Australian Bureau of Statistics (ABS) 2006. Year Book Australia, 2006: Australian Deserts. ABS, Canberra, ACT.

Australian Bureau of Statistics (ABS) 2015. General Social Survey, Australia 2014. ABS, Canberra, ACT.

Australian Institute of Aboriginal and Torres Strait Islander Studies (AIATSIS) 2008. Aboriginal Australia (revised edition 2000, reprinted 2008). Canberra: Geoscience Australia and Aboriginal Studies Press.

Barbier, E.B. 1987. The concept of sustainable economic development. Environmental Conservation, 14 (2): 101-110.

Batterbury, S.P.J. and Bebbington, A.J. 1999. Environmental histories, access to resources and landscape change: an introduction. Land Degradation and Development, 10: 279289.

Beer, A., S. Tually, et al. 2013 Australia's country towns 2050: What will a climate adapted settlement pattern look like? Gold Coast, Qld, National Climate Change Adaptation Research Facility: 139 pp.

Braimoh, A.K. 2009. Agricultural land-use change during economic reforms in Ghana. Land Use Policy, 26 (3): 763-771.

Brown, A. and J. Gonder 2014. An Analysis of Possible Energy Impacts of Automated Vehicles. TRB 93rd Annual Meeting Compendium of Papers: 21.

Brook, B.W., Sodhi, N.S. and Bradshaw, C.J.A. 2008. Synergies among extinction drivers under global change. Trends in Ecology and Evolution, 23 (8): 453-460.

Brooks, G. and Yusuf, F. 2009. Household expenditure on domestic fuel and power in New South Wales, Australia. European Journal of Management, 9: 91+

Cairney, S. and Abbott, T. 2014. Aboriginal Wellbeing in a 'Red Dirt Economy'. Journal of Australian Indigenous Issues, 17 (4): 5-22. 
Centre for Appropriate Technology (CAT) 2013. Housing Experience: Post Occupancy Evaluation of Alice Springs Town Camp Housing 2008-2011, Centre for Appropriate Technology, Alice Springs, NT.

Center for Automotive Research (CAR) 2014. Advanced Information Technology Solutions: An Engine of Innovation. USA.

Chandler, M. J., Lalonde, C. E., Sokol, B. W., \& Hallett, D. 2003. Personal persistence, identity development, and suicide: A study of Native and non-Native North American adolescents. Monographs of the Society for Research in Child Development, 68 (2), Serial No. 273.

Commonwealth Government. 2014. PIVOT NORTH: Inquiry into the Development of Northern Australia: Final Report Joint Select Committee on Northern Australia.

CSIRO and Bureau of Meteorology. 2007. Climate change in Australia. Technical Report, 140 pp, www.climatechangeinaustralia.gov.au.

Davies, J. and Holcombe, S. 2009. Desert knowledge: integrating knowledge and development in arid and semi-arid drylands. GeoJournal, 74 (5): 363-375.

Department of Infrastructure and Regional Development 2014. Trends Infrastructure and Transport to 2030. Australia.

Department of Transport and Main Roads 2013. Moving Freight: A Strategy for More Efficient Freight Movement. Government of Queensland, Australia.

Diesendorf, M., D. Lamb, et al. 2010. Fuelling Future Passenger Vehicle Use in Australia. An Alternative Fuel and Technology Mix for Passenger Vehicles in Australia. The Electric Vehicles Revolution, The Jamison Group.

Dockery, A.M. (2016), “A wellbeing approach to mobility and its application to Aboriginal and Torres Strait Islander Australians", Social Indicators Research, Vol. 125, No. 1, pp. 243-255.

Doll, C., S. Klug, et al. 2014. Large and Small Numbers: Options for Quantifying the Costs of Extremes on Transport now and in 40 years. Natural Hazards, 72 (1): 211-239.

Garnaut, R. (2008). The Garnaut Climate Change Review: Final Report: Cambridge University Press, Cambridge, UK.

Geoscience Australia and ABARE, 2010. Australian Energy Resource Assessment. Report 2010. Geoscience Australia, Canberra, ACT.

Groenfeldt, D. 2003. The future of indigenous values: cultural relativism in the face of economic development. Futures, 35 (9): 917-929.

Grothmann, T. and Patt, A. 2005. Adaptive capacity and human cognition: The process of individual adaptation to climate change. Global Environmental Change, 15 (3): 199213.

Habibis, D. 2011. A framework for reimaging indigenous mobility and homelessness. Urban Policy Research, 29 (4): 401-414.

Havas, L., Ballweg, J., Penna, C. and Race, D. 2015a. Power to Change: Analysis of household participation in a renewable energy and energy efficiency program in Central Australia. Energy Policy (accepted February 2015). 
Havas, L., Ballweg, J., Penna, C. and Race, D. 2015b. Energising Households: A financial analysis of incentivised energy efficiency measures in remote Australia. Energy Efficiency (published online February 2015).

Hunter, B. 2012. Selected Issues for Closing the Income Gaps between Indigenous and other Australians, 2001-11. Aboriginal Economic Policy Research, ANU College of Arts \& Social Sciences CAEPR Topical Issue No: 1/2012.

Hurni, A. 2007. Marginalised Groups in Western Sydney: The Experience of Sole Parents and Unemployed Young People. G. Currie, J. Stanley and J. Stanley (eds) No way to go: Transport and social disadvantage in Australian communities. Melbourne, Vic, Monash University Press.

Intergovernmental Panel on Climate Change (IPCC) 2014. Climate Change 2014: Synthesis Report. The Fifth Assessment Report, IPCC. Cambridge University Press, UK.

Jendritzkyl, G. and Tinz, B. 2009. The thermal environment of the human being on the global scale. Global Health Action, 2: 10.

Kefalas, A.G. 2011. On Systems Thinking and the Systems Approach. World Futures, 67 (45): 343-371.

LaFlamme, M. 2010. Sustainable Desert Livelihoods: A cross-cultural framework. DKCRC Working Paper 69, Desert Knowledge CRC, Alice Springs, NT.

Lélé, S.M. 1991. Sustainable development: A critical review. World Development, 19 (6): 607-621.

Lenzen, M., Wier, M., Cohen, C., Hayami, H., Pachauri, S. and Schaeffer, R. 2006. A comparative multivariate analysis of household energy requirements in Australia, Brazil, Denmark, India and Japan. Energy, 31: 181-207.

Litman, T. 2014. The New Transit Safety Narrative. Journal of Public Transportation, 17 (4): 121-141.

Markham, F. and Doran, B. 2015. Equity, discrimination and remote policy: Investigating the centralization of remote service delivery in the Northern Territory. Applied Geography, 58: 105-115.

Maru, Y.T., Mark, S.S., Pinho, P.F. and Dube, O.P. 2014. A linked vulnerability and resilience framework for adaptation pathways in remote disadvantaged communities. Global Environmental Change, 28: 337-350.

Maru, Y.T., Chewings, V. and Sparrow, A. 2012. Climate change adaptation, energy futures and carbon economies in remote Australia: a review of the current literature, research and policy. CRC-REP Working Paper CW005. Ninti One Limited. Alice Springs, NT.

McMichael, A., Woodruff, R., Whetton, P., Hennessy, K., Nicholls, N., Hales, S., Woodward, A. and Kjellstrom, T. 2002. Human health and climate change in Oceania: a risk assessment. Australian Government, Canberra, ACT.

Memmott, P., Long, S. and Thompson, L. 2006. Indigenous Mobility in Rural and Remote Australia: Final Report. Australian Housing and Urban Research Institute, Aboriginal Environments Research Centre, and Queensland Centre for Population Research, University of Queensland, http://www.ahuri.edu.au/publications.

Moran, M., Wright, A., Renehan, P., Szava, A., Rich, E. and Beard, N. 2007. The Transformation of Assets for Sustainable Livelihoods in a Remote Aboriginal 
Settlement. DKCRC Research Report 28, Desert Knowledge CRC, Alice Springs, NT.

Morton, S. R., Stafford Smith, D. M., Dickman, C. R., Dunkerley, D. L., Friedel, M. H., McAllister, R. R. J., Reid, J. R. W., Roshier, D. A., Smith, M. A., Walsh, F. J., Wardle, G. M., Watson, I. W. and Westoby, M. 2011. A fresh framework for the ecology of arid Australia. Journal of Arid Environments, 75 (4): 313-329.

National Climate Change Adaptation Research Facility (NCCARF) 2013. Adaptation and First Australians: lessons and challenges. Policy Guidance Brief \#6, NCCARF, Griffith University, Gold Coast, Australia.

Newton, P. and Meyer, D. 2012. The Determinants of Urban Resource Consumption. Environment and Behaviour, 44: 107-135.

Peet, R. and Hartwick, E. 2009. Theories of Development: Contentions, arguments, alternatives. 2nd ed. Guilford Press.

Pickering, K. 2000. Alternative economic strategies in low-income rural communities: TANF, labor migration and the case of the Pine Ridge Indian Reservation. Rural Sociology, 65 (1): 48-167.

Pittock, B. 2009. Co-benefits of large-scale renewables in remote Australia: energy futures and climate change. The Rangeland Journal, 33 (4): 315-325.

Productivity Commission 2014. Overcoming Indigenous Disadvantage: Key indicators 2014. Productivity Commission, Australian Government, Canberra, ACT.

Race, D., Luck, G. and Black, R. 2011. Patterns and implications of demographic change in rural landscapes (Chapter 1). In: Luck, G., Race, D. \& Black, R. (eds) Demographic change in Australia and environmental implications. Springer Publications.

Race, D., Campbell, M., Hampton, K., Foster, D., Fejo, C. and Robertson, D. 2014. Observations of Climate Change by Remote Communities: Lessons from the Bush in Central Australia. Journal of Australian Indigenous Issues, 17 (4): 23-39.

Race, D., Mathew, S., Campbell, M. and Hampton, K. 2015a. Understanding climate adaptation investments for communities living in desert Australia: Experiences of indigenous communities. Climatic Change (in press).

Race, D., Mathew, S., Campbell, M. and Hampton, K. 2015b. Are Australian Aboriginal communities sustainably adapting to warmer climates? A study of communities living in semi-arid Australia. Climate and Development (submitted).

Ray, D. 1998. Development Economics. Princeton University Press, US.

Ren, Z., Chen, Z. and Wang, X. 2011. Climate change adaptation pathways for Australian residential buildings. Building and Environment, 46: 2398-2412

Seabrook, L., McAlpine, C.A. and Bowen, M.E. 2011. Restore, repair or reinvent: Options for sustainable landscapes in a changing climate. Landscape and Urban Planning, 100 (4): 407-410.

Sircar, I., Sage, D., Goodier, C., Fussey, P. and Dainty, A. 2013. Constructing resilient futures: Integrating UK multi-stakeholder transport and energy resilience for 2050. Futures, 49: 49-63.

Spandonide, B. 2014. Transport systems in remote Australia: Transport costs in remote communities. CRC-REP Working Paper CW017, Ninti One Ltd, Alice Springs, NT. 
Stafford Smith, M. and Cribb, J. 2009. Dry Times: A Blueprint for a Red Land. Melbourne: CSIRO Publishing.

Stafford Smith, D.M. and Huigen, J. 2009. From Desert Syndrome to Desert System: Developing a science of desert living. Journal of the Academy of the Social Sciences in Australia, 28 (2): 8-18.

Stern, N. 2006. The Economics of Climate Change: The Stern Review, Cambridge University Press, UK.

Taylor, P.G., d' Ortigue, O.L., Francoeur, M. and Trudeau, N. 2010. Final energy use in IEA countries: The role of energy efficiency. Energy Policy, 38: 6463-6474.

Tiplady, T. and Barclay, M.A. 2007. Indigenous Employment in the Australian Minerals Industry. Report by the Centre for Social Responsibility in Mining, Sustainable Minerals Institute, University of Queensland.

Tonkinson, R. 2007. Aboriginal 'difference' and 'autonomy' then and now: Four decades of change in a Western Desert society. Anthropological Forum: A Journal of Social Anthropology and Comparative Sociology, 17 (1): 41-60.

Turner, K. R. 1988. Sustainable environmental management: Principles and practice. Belhaven Press, UK.

United Nations Environment Programme (UNEP) 2006. Global Deserts Outlook. UNEP, Nairobi, Kenya.

Velaga, N.R., Beecroft, M., Nelson, J.D., Corsar, D. and Edwards, P. 2012. Transport poverty meets the digital divide: accessibility and connectivity in rural communities. Journal of Transport Geography, 21: 102-112.

Walker, B. 2015. Radicalising the Rangelands: disruptive change or progressive policy? The Rangeland Journal (submitted).

Wang, X., Chen, D. and Ren, Z. 2010. Assessment of climate change on residential heating and cooling requirement in Australia. Building and Environment, 45: 1663-1682.

Went, A., Newman, P. and James, W. 2008. Renewable Transport: How energy and electric vehicles using vehicle to grid technology can make carbon free urban development. CUSP Discussion Paper 2008/1, Curtin University Sustainability Policy Institute, Perth, WA. 